\title{
Nano technology for green mobility and sustainable development in rubber industry
}

\author{
R Mukhopadhyay
}

\begin{abstract}
Hari Shankar Singhania Elastomer \& Tyre Research Institute (HASETRI), JK Tyre \& Industries Ltd \& Chairman-Indian Rubber Institute (IRI)

Email: rm@ktp.jkmail.com,rm.hasetri@gmail.com
\end{abstract}

Economies today have two major challenges: The need to create a sustainable growth oriented economy, and the need to be competitive in the global market. Our current economic model based on fossil fuels, unbridled consumption and throwaway products is just not sustainable. So, the solution must be "sustainable growth" through Green Technology, a way to grow that creates both economic and societal values while, at the same time, reducing overall environmental impacts. This will only possible through green technology innovation, the only lasting and sustainable way to make the necessary transformations across the industry to save our mother planet.

The rapidly advancing field of Nano technology has the potential to impact industrial and economic development, the environment and society at a global level. However, the diverse nature of nano technology application across different industrial sectors make it difficult to analyse the impact of those policies and regulation targeted at promotion of technology, investment, commercialization and human \& environmental protection. Today, the tyres $\&$ other rubber products by far the biggest commercial market for nano materials. Modern tyres achieve their high mileage, durability, fuel efficiency and road grip (safety), through the use of nano scale carbon black and precipitated silica. New generation nano material could provide dramatic improvements over existing technologies in rubber industry for green mobility and sustainable development.

The green technology and environmental sustainability in rubber industry are addressed through:

- A new "Ecosystem" of collaborative partnership among Regulatory innovation frontier (Government), Business innovation frontier (cross industry value chain) and Technical innovation frontier (Auto industry)

- Design for Environment (DFE): New concept development (dematerialization through use of nano materials, shared use of the product, integration of functions, functional optimization of production \& components), Selection of low impact materials (non hazardous material, non exhaustible materials, low energy content material, recycled material \& recyclable material), Reduction of material (reduction in weight, reduction in transport volume), Optimisation of production techniques (fewer production process, low/clean energy consumption, low generation of waste and few/clean production consumables), Efficient distribution system, Reduction of environmental impact in the user stage (low energy consumption, clean energy source, few/new consumables needed during use \& no energy/auxiliary material use), Optimisation of initial life time (reliability and durability, easy maintenance $\&$ repair, modular product structure, classic design and user taking care of the product) Optimisation of end of life system (reuse, remanufacturing/refurbishing, recycling of material \& clean incineration)

- Cleaner production through continuous application integrated preventive environmental strategy applied to process, product and services to increase overall efficiency and reduce risks to human and the environment.

- Resource optimisation through material and energy balances

The potential of eco friendly sustainable green technology is unlimited and throws substantial challenges before the scientific and engineering community associated with Rubber \& Allied industry. 